RESENHA

\title{
Descolonizando metodologias: pesquisa e povos indígenas
}

\author{
Maria Aparecida Bergamaschi ${ }^{1}$ \\ Isael da Silva Pinheiro ${ }^{1}$ (D)
}

SMITH, L. T. Descolonizando metodologias: pesquisa e povos indígenas. Trad. Roberto G. Barbosa. Curitiba: Editora UFPR, 2018.

"Da perspectiva do colonizado, uma posição a partir da qual eu escrevo e escolho privilegiar, o termo 'pesquisa' está indissociavelmente ligado ao colonialismo e ao imperialismo europeu" (Smith, 2018, p. 11). Assim inicia o livro de Linda Tuhiwai Smith, intelectual indígena maori da Nova Zelândia, publicado originalmente no ano de 1999 pela Zed Books, London, e agora publicado no Brasil, com a tradução para o português de Roberto G. Barbosa. A frase inicial anuncia o tom do livro, que faz uma análise crítica do papel colonizador de pesquisas e pesquisadores junto a povos indígenas e, igualmente, traz uma importante contribuição para as metodologias descolonizadoras, sendo essa, talvez, a obra que mais tenha influenciado as pesquisas indígenas nas duas últimas décadas.

A autora é professora na Universidade de Waikato, em Hamilton, Nova Zelândia, e se autodeclara Ngāti Awa, Ngāti Porou. Além disso, é considerada uma das principais expoentes mundiais dos estudos indígenas e da educação indígena, bem como da pesquisa Kaupapa Maori ${ }^{1}$, deixando evidente, em seu trabalho, o "compromisso com o bem-estar e a autodeterminação intelectual e política dos povos indígenas", como afirma ao se apresentar no site de sua universidade ${ }^{2}$. Ainda estudante, militou em um grupo de jovens maori, reivindicando que a língua originária desse povo fosse ensinada nas escolas, foi professora primária, coordenadora de ensino médio, pesquisadora na área da saúde e, por fim, professora universitária.

O livro Descolonizando metodologias: pesquisa e povos indigenas busca desconstruir a colonialidade do conhecimento ocidental e fortalecer modos originários próprios, evidenciando outras possibilidades de realizar pesquisa junto aos povos

1 Abordagem teórico-metodológica própria, inspirada e fundamentada na filosofia maori (Smith, 2018).

2 Disponível em: https:/www.waikato.ac.nz/maori/linda-tuhiwai-smith. Acesso em: 26 fev. 2020.

${ }^{1}$ Universidade Federal do Rio Grande do Sul, Porto Alegre, RS, Brasil. 
indígenas. Smith (2018) parte do posicionamento de que o conhecimento científico hoje predominante foi desenvolvido por meio de práticas racistas, que contribuíram para discriminar e desvalorizar os povos indígenas. A professora dá exemplos de pesquisas com resultados que afirmam a inferioridade dos povos originários, situação ainda presente nas memórias coletivas. Ainda, questiona ações colonizadoras que negam a legitimidade de reivindicações básicas, como o direito à terra e aos territórios, à autodeterminação, às línguas originárias, aos conhecimentos próprios. A autora reconhece que os povos indígenas desenvolveram suas próprias formas de resistência, criando outras visões de mundo, também por meio da pesquisa, e que hoje podem ser usadas para enfrentar o colonialismo e a opressão ocidental.

A chegada do livro ao Brasil vem gerando estudos e reflexões, principalmente entre os pesquisadores e as pesquisadoras indígenas que, ainda de forma inicial, estão presentes nos programas de pós-graduação de universidades brasileiras, afirmado a necessidade de produzir conhecimentos e metodologias próprias nas pesquisas realizadas. "De objetos de pesquisa, passamos a ser pesquisadores" - frase de Smith que também ecoa entre pesquisadores indígenas brasileiros, os quais se somam a autora para dizer: "queremos contar a nossa própria história, escrever as nossas próprias versões, a nossa maneira, para os nossos próprios fins”(Smith, 2018, p. 42). São posturas que afirmam a autoria indígena nos espaços acadêmicos de pesquisa.

O livro está organizado em dez capítulos, que compõem duas partes, além da introdução e da conclusão. Na primeira parte, composta por quatro capítulos, a autora aborda imperialismo, pesquisa e conhecimento e remete à história da pesquisa ocidental junto aos povos indígenas, tecendo críticas às premissas culturais que estão por trás das práticas coloniais. Smith vai mostrando porque os povos indígenas, de um modo geral, têm aversão à pesquisa e a pesquisadores, bem como ainda mantêm uma desconfiança necessária e prudente. Em um estudo aprofundado, assentado em inúmeros exemplos, analisa os conceitos de imperialismo e colonialismo e as interferências que ambos produziram sobre os colonizados. Dessa forma, mostra que, para os povos indígenas, a pesquisa tem um significado implícito na própria história, sob o olhar da ciência e do imperialismo ocidental. Questiona o lugar da escrita, das teorias impostas e das histórias, que hoje são contestadas.

A autora sustenta que "a pesquisa através dos olhos imperiais" provém de um "arquivo de conhecimentos e sistemas, regras e valores que se estendem para além da ciência ocidental” (Smith, 2018, p. 57). Detalha como se deram as formações culturais da pesquisa ocidental, analisa as conceituações de indivíduo e de sociedade, bem como as concepções de espaço e de tempo, contrapondo imposições coloniais aos modos próprios de conceber essas questões. Mostra, por meio de um posicionamento crítico, que a pesquisa através dos olhos imperiais assume as ideias ocidentais provindas do iluminismo e concebidas como as únicas possíveis e racionais para dar sentido ao mundo, à realidade, à vida social e aos humanos.

Para a autora, o conhecimento e a ciência ocidental muito se favoreceram com a colonização dos povos indígenas, e esse conhecimento, produzido por meio da colonização, tem sido usado para colonizá-los ainda mais. Também, denuncia processos de dominação e exemplifica práticas de pesquisa e sistemas de coleta de informações, desde os relatos deixados pelos viajantes do passado até as pesquisas 
atuais, evidenciando formas de domínio e usurpação de conhecimentos indígenas. Mostra, igualmente, como se estabeleceu a superioridade posicional do conhecimento ocidental, constatando que "nas bases científicas da pesquisa ocidental, as contribuições indígenas raramente são mencionadas" (Smith, 2018, p. 78). Ainda na primeira parte do livro, a autora apresenta os modos de vida dos povos indígenas da Nova Zelândia, refletindo sobre as novas linguagens do imperialismo, presentes também nos processos investigativos, lista dez maneiras de ser pesquisado (colonizado), revela sonhos e desafios dos povos indígenas frente aos novos modos de conquista.

Adentrando na segunda parte do livro, na qual há proposições, a autora anuncia uma perspectiva descolonizadora, apresentada especialmente no capítulo $O$ projeto dos povos indigenas: definindo uma nova agenda. Smith apresenta diferentes abordagens $\mathrm{e}$ metodologias que estão sendo desenvolvidas para assegurar que pesquisas com povos indígenas sejam mais respeitosas, éticas, solidárias e úteis. Ademais, expõe a concepção de pesquisa-ação comunitária e emancipatória, nas quais as comunidades participam e decidem caminhos nos processos investigativos. Nesse sentido, sugere várias formas de fazer pesquisas na perspectiva da autodeterminação. Também, analisa o movimento indígena, as mobilizações e os acordos internacionais que afirmam direitos, inclusive no campo da pesquisa. A autora apresenta a pesquisa kaupapa maori como um caminho rumo ao desenvolvimento de metodologias e protocolos éticos próprios, propiciando considerar o quão colonial ainda são as práticas e protocolos no Brasil, ao não reconhecerem a autodeterminação dos povos indígenas, tratando-os como vulneráveis e incapazes.

Nos últimos capítulos do livro, Smith deixa mais evidente que a pesquisa compreendida e empreendida pelos povos indígenas é diferente daquela desenvolvida a partir dos olhos imperiais. Além disso, rejeita o termo pós-colonialismo, pois entende que o colonialismo não terminou e argumenta que ainda é causa de profundos impactos; mostra que os paradigmas coloniais se apresentam de várias maneiras, marginalizando e inferiorizando os povos indígenas. A autora direciona cada vez mais a sua escrita para pesquisadores e pesquisadoras indígenas e aqueles que trabalham com a pesquisa maori, contribuindo, assim, para construir uma agenda para pesquisas indígenas. Ainda, retoma os vários problemas que ainda são recorrentes no campo da pesquisa e que precisam ser superados a partir dos próprios povos. Discute processos de descolonização e defende o valor da pesquisa para os povos indígenas, que têm questões singulares e importantes para responder. Também, reforça a necessidade de recuperar espaços em que pessoas e coletivos indígenas ainda são excluídos e marginalizados, apontando à necessidade de desenvolver agendas no caminho da autodeterminação.

Linda Tuhiwai Smith conclui o livro discorrendo, de forma inspiradora, sobre a sua jornada pessoal, de como adentrou e como se sente no mundo da pesquisa, ponderando sua visão acerca dos novos pesquisadores indígenas. Relata dificuldades encontradas e os desafios de ser indígena e pesquisadora, situação nem sempre benéfica para as comunidades de origem. Destaca, ainda, a importância da pesquisa para os povos indígenas e mostra que somente estratégias e conhecimentos próprios poderão transformar a pesquisa em um meio de luta e resistência contra a dominação colonial. Como pesquisadora indígena, evidencia a necessidade de os próprios povos elegerem suas prioridades de pesquisa e resistirem a novas formas de colonização, afirmando: "Nossas questões são importantes. A pesquisa nos ajuda a respondê-las”(Smith, 2018, p. 226). 
A partir dos exemplos maori apresentados e refletidos por Smith, que, certamente, são singulares, decorrem contribuições para inspirar práticas de pesquisa que superem a hegemonia do paradigma ocidental ainda muito presente na academia, que gera racismo, o livro afirma o eurocentrismo e mantém a colonização. Trata-se de uma obra de suma importância para os pesquisadores indígenas e não indígenas que almejam uma prática respeitosa, colaborativa e intercultural. Descolonizando metodologias: pesquisa e povos indígenas deixa muitas interrogações e diz ser imperativo que cada vez mais os próprios indígenas realizem suas pesquisas, com a compreensão da necessidade de ocuparem lugares dos quais foram historicamente excluídos.

\section{REFERÊNCIA}

SMITH, L. T. Descolonizando metodologias: pesquisa e povos indígenas. Trad. Roberto G. Barbosa. Curitiba: Editora UFPR, 2018.

\section{SOBRE OS AUTORES}

Maria Aparecida Bergamaschi é doutora em educação pela Universidade Federal do Rio Grande do Sul (UFRGS). Professora da mesma instituição. E-mail: cida.bergamaschi@gmail.com

Isael da Silva Pinheiro é doutorando em educação pela Universidade Federal do Rio Grande do Sul (UFRGS), bolsista do Conselho Nacional de Desenvolvimento Científico e Tecnológico (CNPq). E-mail: isaelsp.edu@hotmail.com

Conflitos de interesse: Os autores declaram que não possuem nenhum interesse comercial ou associativo que represente conflito de interesses em relação ao manuscrito.

Financiamento: $\mathrm{O}$ estudo não recebeu financiamento.

Contribuições dos autores: Administração do Projeto, Análise Formal, Conceituação, Curadoria de Dados, Escrita - Primeira Redação: Bergamaschi, M.A; Pinheiro, I. S. Revisão e Edição: Bergamaschi, M.A; Pinheiro, I. S.

Recebido em 16 de junho de 2020 Aprovado em 2 de março de 2021 